\title{
MUJERES BÍBLICAS COMO MODELOS DE CONDUCTA FEMENINA A FINALES DE LA EDAD MEDIA
}

\author{
Dulce M.a González Doreste \\ Instituto de Estudios Medievales y Renacentistas - Universidad de La Laguna \\ ddoreste@ull.edu.es
}

\section{RESUMEN}

Este trabajo se inscribe en el proyecto titulado «Arquetipos femeninos en los tratados medievales franceses para la educación de las mujeres» (MINECO FFI-2016-76165-P), que se desarrolla actualmente en el ámbito del Instituto de Estudios Medievales y Renacentistas de la Universidad de La Laguna (IEMYR). Tiene por objeto el estudio de aquellos paradigmas de comportamiento femenino que se repiten en distintas obras medievales, escritas en francés y destinadas a la instrucción de las mujeres, con el fin de servirles de modelos de conducta. Muchos de estos arquetipos están tomados de la Biblia (Susana, Sara, Rebeca, Betsabé, Ester, Judith, etc.) y forman parte de una tradición anterior que ha ido dándoles forma hasta constituirse en ejemplos a seguir por las mujeres en la Edad Media.

Palabras ClaVE: Mujeres, Biblia, tratados medievales franceses.

BIBLICAL WOMEN AS A FEMALE BEHAVIOR MODEL IN THE MIDDLE AGES

\section{ABSTRACT}

This paper is part of the research project «Female Archetypes in French Medieval Treatises for Women's Education» (MINECO FFI-2016-76165-P), which is being carried out within the Institute of Medieval and Renaissance Studies (IEMYR) at Universidad de La Laguna. The aim of this paper is to analyze the paradigms of female behavior which are repeated in different medieval works written in French and concerned with instructing women, thus offering models of behavior. Many of these archetypes are taken from the Bible (Susanna, Sarah, Rebekah, Bathsheba, Esther, Judith, etc.) and they are linked to a former tradition which shaped them until they became role models for women in the Middle Ages.

KeY WORDS: Women, Bible, French Medieval Treatises.

\section{INTRODUCCIÓN}

Nos centraremos en el estudio de las figuras bíblicas femeninas que aparecen en dos obras escritas a final de la época medieval y principios del siglo XVI de distinta índole, en cuanto a su estructura textual, pero ambas de carácter didáctico y 
con el objetivo de servir de instrucción a las mujeres. Aunque muy diferentes en cuanto a la forma, ambas obras siguen la tradición mitográfica medieval, inaugurada por Boccaccio que tendrá pervivencia hasta bien entrado el siglo XVII con las célebres "galéries de femmes illustres». Como la crítica especializada no les ha prestado la misma atención que a otros tratados, nos detendremos en primer lugar en una breve presentación de sus características. Se trata de Le parement et triumphe des femmes, (1492-1493), conocida también como Le triumphe des femmes' ${ }^{1}$ de Olivier de la Marche y La nef des dames vertueuses (1503) de Symphorien Champier.

La obra de Olivier de la Marche, todavía con un barniz de espíritu medieval, sólo puede considerarse indirectamente ligada a la Querella de las Mujeres², ya que es su antecesora, el Triunfo de las Donas (1440), de Juan Rodríguez del Padrón, la que se inscribe directamente en la polémica surgida en la corte de Castilla, como reacción a la publicación de la obra, de carácter marcadamente misógino, de Alfonso Martínez de Toledo El Corbacho (1438). El texto de Rodríguez del Padrón es una respuesta a ésta, encargada por la Reina María de Castilla para resarcir a las mujeres de las humillaciones y vituperios vertidos por el Arcipreste. Sin embargo, unos años después, el autor de La nef des dames vertueuses toma partido en la controversia a favor de las mujeres, considerando que su escaso acceso al conocimiento las pone en una situación de debilidad frente a los hombres.

Acudiremos también a otros tratados anteriores, más conocidos, en los que se citan algunos de los modelos bíblicos contenidos en estos dos. Acudiremos también a otros tratados anteriores, más conocidos, en los que se citan algunos de los modelos bíblicos contenidos en estos dos, con el fin de examinar las distintas adaptaciones de estos relatos en diferentes obras y periodos.

\section{LE PAREMENT ET TRIUMPHE DES FEMMES (1493-1494)}

El autor de esta sorprendente obra, Olivier de La Marche (1425-1502) ${ }^{4}$, perteneció a una antigua familia de la Borgoña, de cuyos primeros miembros se encuentran

${ }^{1}$ Florence Serrano informa de la existencia de otro tratado con el título del Triumphe des dames, que había circulado treinta años antes de la aparición del de Olivier de La Marche por la corte burguiñona, y que se trata de la traducción al francés de un tratado alegórico-didáctico castellano redactado por Juan Rodríguez del Padrón en torno al año 1440 con el título de Triunfo de las donas (2009: 55).

${ }^{2} \mathrm{Al}$ final de su trabajo, la misma autora identifica un corpus de textos burguiñones asociados directamente a la Querelle des femmes por su carácter polémico y argumentativo, como el Champion des dames, de Martin le Franc, y el Triumphe des dames, y, de forma indirecta, las Cent Nouvelles nouvelles y el Triumphe des dames de Olivier de La Marche (2009: 71).

${ }^{3}$ Seguimos la edición de Julia Kalbfleisch-Benas (1901).

${ }^{4}$ Ver Tyl-Labory, Gillette, "Olivier de La Marche», Dictionnaire des lettres françaises: le Moyen Âge, 1994, pp. 1085-1086. 
testimonios, según la genealogía trazada por Henri Stein, desde 1174, si bien es imposible, dicho por el propio biógrafo, establecer con certeza la filiación de todos los La Marche encontrados a lo largo de su investigación (1888: 7-13). Desde muy joven entró en la corte al servicio de Felipe III, Duque de Borgoña, llamado "Felipe el Bueno", donde pasará toda su vida. Gracias a sus Mémoires, que ocuparán cincuenta y tres años de su biografía (1435-1488), ha sido posible conocer con detalle su agitada existencia, así como los pormenores de la vida de la corte y la memoria de una época, sobre todo relativa a los acontecimientos que afectaron a la casa de Borgoña. Su penetrante sentido de la observación le procurará un ingente material para su prolífica obra poética entre la que destaca el Chevalier délibéré (1483), cuyo carácter simbólico anuncia ya el tono alegórico y didáctico que tomará Le parement et triumphe des femmes. Esta obra, que es la que más nos interesa para nuestro objetivo de toda la producción de Olivier de La Marche, fue escrita durante su retiro en Malines en 1488, donde pasará los últimos años de su vida, dedicado a la escritura, hasta su muerte en Bruselas el 1 de febrero de 1502. Está escrita en estrofas de ocho versos octosilábicos en las que se describe un accesorio de la vestimenta femenina al que se le confiere en las últimas un sentido moral y didáctico, convirtiendo la pieza a la que se refiere (cinturón, pantuflas, etc.) en una virtud simbólica. A esta parte en verso le sigue otra en prosa que expone las hazañas de un personaje femenino, digno representante de la cualidad que ilustra 5 . Siguiendo la tradición mitográfica medieval, La Marche reunió figuras cristianas y paganas que, en palabras de Élisabeth Gaucher, «se pressent sous la plume du moraliste à la manière d'un assemblage de pièces multicolores qui formeront le patchwork du texte» (2006: 10). Las intenciones de este texto, según declara el propio autor en la primera de sus estrofas, dejan entrever su afán didáctico. Su propósito es pasar revista a las virtudes que la dama debe poseer para ser digna de un amor entregado que no sea causa de sufrimiento del caballero amante:

L'autr'ier passant une nuyt de decembre aprés dormir, que l'esperit medite, amours me vint assaillir et surprendre des grans vertus, qui ne sont a conprendre, d'une dame, mon chois et mon eslite. Mon coeur la m'a destinee et predite; or fault sçavoir se je la doibz aimer d'amour amere ou d'amours sans amer (p. 1)

${ }_{5}^{5}$ La utilización del exemplum y listas laudatorias en las obras de los moralistas es una práctica habitual en la Edad Media y el Renacimiento. Su presencia en los tratados didácticos no tiene otra finalidad, retomando las palabras de Manuela Álvarez Jurado, «que la revelar una serie de virtudes representativas en los diferentes "personnages exemplaires", que servirían de paradigma, de modelo de conducta a los lectores» (2001: 10). 
Sin embargo, como declarará más tarde, a medida que va desgranando sus glosas, su libro se convertirá en un miroir d'entendement, en un manual de educación en definitiva donde quedan recogidas las virtudes y modelos de conducta que las damas deben imitar. Como lo sintetiza Gaucher, «il n'y est plus question de la dame aimée, seulement des dames à éduquer» (2006: 13):

Ce miroir cy sera d'entendement
tout composé ildustré et bruny.
La peult madame veoir tout clerement
ou est le biau, le lait samblablement,
ou est bonté et ou sens a failly,
so l'onneur croist ou s'il est amendry,
se l'ame est necte ou s'elle est empeschee.
Se miroir cy monstre tout de visee (p. 91 ).

\subsection{Figuras bíblicas femeninas en Le parement et triumphe des femmes}

No es fácil, a primera vista, asociar la relación del complemento de la vestimenta de una dama con una virtud. El procedimiento que La Marche va a seguir en las estrofas dedicadas a cada uno de los complementos que evocan la vestimenta de la dama, será primero la descripción del objeto, después su utilidad material y finalizará con la identificación razonada de esa pieza con una virtud. Se trata, pues, de un conjunto de metáforas desarticuladas que van construyendo el tejido textual, hilvanadas por una operación de identificación de lo concreto, el objeto, con lo figurado o abstracto, una cualidad o virtud. Será la glosa en prosa, la que propondrá la filiación de dicha cualidad con una conducta ejemplar protagonizada por las mujeres que la representan.

Los zapatos: Abigail (1901: 6-8). De esta forma, los zapatos son considerados una pieza fundamental que deben ser confeccionados por un buen artesano para no dañar el delicado pie de la dama. Le permiten caminar con paso ligero y elegante sin dañarse los pies y son de tal importancia que pueden llegar a salvar un reino o el honor de la dama. Por ello, uno será llamado «soing» y el otro «diligence», virtudes que se oponen a la "paresche» y a la «negligence». Dios aprueba la diligencia y guía por el buen camino para que alcance sus aspiraciones al caminante que se adorna con ella.

La glosa de los zapatos evoca la historia de Nabal y Abigail. Contada sucintamente y dando especial relevancia a la crueldad e insolencia de Nabal hacia David, La Marche incide igualmente en la presteza de Abigail para impedir la masacre de su pueblo presentándose humildemente ante el israelita con abundante comida, lo que le valió su reconocimiento y más tarde, después de que Nabal muriera «assez confusement», convertirse en su esposa. La moral de la historia es clara y se dirige a todas las mujeres: "Ceste Abigayl nous aprent et enseigne que dilligence est moult necessaire a toutes dames; car on en peult moult de maulx eschever» (1901: 8). 
El cuchillo: Judith (1901: 40-45). Nuestro autor considera imprescindible que las mujeres, ya estén en pueblo o en ciudad, lleven consigo un pequeño cuchillo, «un coustelet», para defenderse en caso de apuro. Además del servicio que les prestan estos utensilios en el servicio de mesa, considera que pueden servirles también «a tout besoing qui lui peult sourvenir». Se trata, pues, de un objeto de defensa personal, nunca daga o espada, que debe llevar colgado de un cordón de seda, de mango suave y de lama afilada, más o menos lujoso en función de la calidad de la dama. La virtud análoga al cuchillo es la justicia y simboliza también la protección de la dama, encumbrada de dicha virtud, contra todos los vicios que la acechan. El mango suave representa la conducta cortés y dulce de la dama que puede tornarse implacable cuando la ofensa exige justicia. Termina en la última estrofa por invocar el deber de la mujer, ya sea burguesa, reina o campesina, de hacer justicia tanto para sí mismas como por el bien público.

La figura de Judith, hermosa viuda y casta, le parece la más acertada para encarnar esta virtud. Expone con detalle en su glosa en verso el relato, bien conocido en la época, de esa bella mujer que con «sa femenine main» decapitó a Holofernes e hizo justicia con aquel tirano contra el que diez mil hombres no osaron enfrentarse, exhortando a las damas a seguir su ejemplo pues es voluntad de Dios que la justicia se ejecute «aussy bien par les femmes que par les hommes».

El vestido: Ester (1901:54-57). No es extraño que para Olivier de La Marche, que vivió rodeado del lujo de la corte, la dama de renombre y de sangre real deba cubrir su cuerpo con lujoso vestido tejido en oro, de color púrpura y con rica capa de armiño para que los ojos de los que la admiran sientan placer al verla relucir. Desde el punto de vista moral, esa hermosa apariencia esconde una gran virtud que el autor va a denominar «la vertu du maintien», la actitud recatada. De la misma forma que la apariencia puede cautivar o desagradar, un «beau maitien» se opone a un «fol maintien", un comportamiento ligero y frívolo que ha llevado al deshonor a muchas damas. Se dirige aquí especialmente a las jóvenes, a quienes exhorta a abandonar cualquier ocupación mundana, «laissiés la lettre, tout ouvraige et escolle», para cultivar el «beau maintien», pues no hay en el mundo un tesoro mayor para la mujer que «bonne contenanche». Por otra parte, la capa de armiño que la protege y le da prestancia, significa la virtud de la obediencia, siendo así que la actitud recatada y la obediencia presta son las virtudes que más complacen al hombre: «Le biau maintien, l'obeyssance prompte,/ c'est le moyen qui plus l'omme contente».

En el relato que da contenido a la glosa de estas virtudes, la figura femenina elegida por La Marche para ilustrarlas es Ester. El largo desarrollo que le dedica al relato incluye también la mención a la reina Vasti para establecer la oposición entre una conducta reprobable, la altanería y rebeldía de la primera esposa que le mereció el castigo de ser repudiada por el rey, frente a la humildad, obediencia y sumisión de la reina Ester, su contrapunto modélico, elegida por el rey Asuero de entre las más bellas mujeres de su reino. Estas virtudes, además de hacerla merecedora del título de reina, le ayudaron también a salvar a su pueblo: «Ainsy la royne Hester par son obeyssance gaigna le lieu real que perdit Vasty par sa faulte, et par beau maintien pleust au roy son mary, dont elle saulva son pays, ses parens et sa lignee de perdición». Por todo ello, la conducta de Ester, aconseja el moralista, por los grandes beneficios que les reportará, debe ser emulada por todas las mujeres. 


\section{LA NEF DES DAMES VERTUEUSES $(1503)^{6}$}

En el prólogo de la obra, de carácter alegórico, es el mismo poeta Prudencio quien exhorta a Champier a continuar la labor que emprendió ensalzando a nobles y príncipes en La nef des princes (1502) haciendo esta vez la loa de las mujeres y sus virtudes. A ello dedica el primero de los cuatro libros que componen La nef des dames vertueuses, que titula "Les Louenges fleurs et deffensoir des dames», dedicado a la «tresnoble et tresvertueuse princesse Anne de france dame et duchesse de bourbon et d'auvergne» (p. 55), la célebre Ana de Francia o Ana de Beaujeu, como ella gustaba llamarse, hija de Luis XI y Carlota de Saboya y madre de Susana de Borbón. Para ella su madre escribió un tratado de educación, Les enseignements d'Anne de France... à sa fille Susanne de Bourbon (1503) con la intención de instruirla, tanto en aspectos morales como prácticos, antes de su boda en 1505 con Carlos de Borbón y de Montpensier. Esta dedicatoria pudo ser interesada pues, Champier, médico de profesión, buscaba obtener el título de médico en la corte para así poder dedicarse con más desahogo a su carrera literaria, lo que finalmente no consiguió (Kem, p. 12), aunque la obra tuvo un gran éxito que le valió tres ediciones en 1503, 1515 y $1531^{7}$. Prueba de sus esfuerzos por conseguir el mecenazgo de los Borbones es la extensa genealogía de la familia que pone fin al prólogo y antecede a la dedicatoria. El segundo libro se trata de un tratado sobre el matrimonio destinado a las mujeres en la línea de Enseignements d'Anne de France... à sa fille Susanne de Bourbon', a quien también está dedicado el de Champier; las profecías de las sibilas, traducidas al latín por Lactancio y «en rethorique Françoise par maistre simphorien Champier» ocupan el tercer libro y está dedicado también Ana de Francia. Finalmente, el cuarto libro, titulado «de vraye amour» quiere demostrar «comment et en quoy les dames doivent mettre leur amour», es un sermón laico sobre el Banquete de Platón y se lo ofrece igualmente a Ana de Francia.

La supuesta defensa que Champier hace de las mujeres en este libro, se contradice con la misoginia de la que he hecho gala en su anterior obra, La nef des princes, donde incluye la traducción del texto de Matheolus, La malice des femmes, una compilación de finales del siglo XV, elaborada a partir de versos sacados de Les lamentations de Matheolus (Carlino, A. et Wenger, A., 2007: 56), obra que tanta desazón causó

${ }^{6}$ Seguimos la edición de Judy Kem (2007).

${ }^{7}$ Sobre las ediciones de La nef des dames vertueuses, véase el trabajo de Renée-Claude Breitensteim (2016: 241-257).

${ }^{8}$ En este libro Champier da cuenta de sus conocimientos de medicina en las notas marginales redactadas en latín y que Kem supone estar dirigidas a un público masculino puesto que el mensaje que transmite es que «les organes essentiels pour une bonne conduite morale manquent aux femmes» (p. 36).

${ }^{9}$ El Liber lamentationen Matheoluli o Matheolus fue escrito a finales del siglo XIII y tuvo una gran repercusión en los siglos XIV y XV. Fue traducido al francés por Jean Lefevre en 1380. 
a Christine de Pizan y que está en el origen de la redacción de La cité des dames, según ella misma cuenta ${ }^{10}$.

El primer libro comienza con una introducción en la que su autor argumenta su elogio a las mujeres, frente a los que las acusan por su malignidad y las vituperan, porque en ellas «est toute pitié, toute miséricorde, toute amour, toute doulceur, et toute religión» (pp. 58-59), Seguidamente, esboza, la biografía de cincuenta y siete mujeres de la Antigüedad, «dames anciennes décorées tant par l'éloquence des historiographes que par les divins vers et figments poetiques» (p. 64). En esta parte se percibe la influencia de la obra de Boccaccio De claris mulieribus de la que extrae buena parte de sus biografías, aunque evitando a las mujeres que considera de moralidad más dudosa. Le sigue el grupo de figuras bíblicas y de santas, tomadas en su mayor parte de La légendé dorée, entre otras fuentes, y finaliza enumerando a otras mujeres ilustres que, aún sin haber alcanzado la categoría de santas, son dignas de consideración por lo destacable de sus vidas y de sus obras. Aquí encontramos entre otras a Proba, la doncella de Orleans o a Blanca de Castilla.

\subsection{Figuras bíblicas femeninas en La nef des dames vertueuses}

En la tercera parte del primer libro, «Les Louenges fleurs et deffensoir des dames», que recibe como subtítulo «la fleur des dames», se exponen «les vertus des anciennes dames du viel testament tant de la loy de nature que de la loy escripte» (p. 88). Expondremos a continuación la lista de las figuras femeninas que incluye, sintetizando y destacando especialmente las virtudes por las que Champier cree que su memoria es digna de conservar y de ofrecerlas como modelos a sus lectoras.

Comienza por Eva la pecadora, madre del género humano y formada a partir de la costilla de un hombre justo e inocente, que perdió los cuatro privilegios que Dios le otorgó por su desobediencia. Le sigue la mujer de Noé, merecedora de entrar en la Nave por su paciencia y su colaboración en la alta misión que debió llevar a cabo su marido para salvar a la humanidad del castigo de Dios. Sara, la mujer de Abraham, tiene también un puesto en ella por la fidelidad y humildad que mostró a su marido. Rebeca se distinguió por su extraordinaria belleza y castidad que la hizo digna de ser entregada como esposa a Ysaac. Dios la compensó dándole un hijo, aunque era estéril. La humildad de Lia, la mujer de Jacob, la condujo hasta la Nave. Raquel, hija de Labán, siervo de Jacob, su primo, del que será más tarde su esposa,

${ }^{10}$ En las primeras líneas de su obra, Christine expresa así el desconcierto que le produjo leer la obra de Matheolus: «Mais la lecture de ce livre, quoi qu'il ne fasse aucunement autorité, me plongea dans une revêrie qui me bouleversa au plus profond de mon être. Je me demandais quelles pouvaient être les causes et les raisons qui poussaient tant d'hommes, clercs et autres, à médire des femmes et à vitupérer leur conduite soit en paroles, soit dans leurs traités et leurs écrits» (p. 36). 
fue mujer adornada de grandes virtudes, de las que sobresalen su belleza y su complacencia, por lo que, siendo también infértil, fue premiada con un hijo. La hija del gobernador Putifar, Asnat, fue entregada como esposa a José con quien fue muy feliz y fue colmada de bienes y riquezas por su nobleza. Dina, hija de Lía y de Jacob, ocupa un lugar en la nave por su belleza y sabiduría. Raptada y violada por Siquén, hijo de Jamor, príncipe de la ciudad, fue vengada por sus hermanos, lo que conllevó la destrucción de la ciudad. La historia de Tamar relatada por Champier, está tan sintetizada, como el resto de ellas, que apenas se parece ni explicita los hechos contenidos en el Génesis. Tamar, esposa de Er, hijo a su vez de Judá, es invitada a hacer compañía a las otras damas que han entrado ya a la Nave porque Dios le concedió el beneficio de su protección y le salvó la vida por medio del sello y el cordón que le cedió su suegro. La tradición, como también nuestro autor, suele confundir a la esposa etíope $^{11}$, de Moisés con Seforá siendo en realidad el mismo personaje, la hija de Madián, que es invitada a entrar en la Nave por sus numerosas virtudes y por haber salvado la vida de Moisés de la ira del ángel circuncidando a su hijo con una piedra afilada. Champier reserva un sitio a María, la hermana de Aarón, por su virginidad, por su inteligencia, por ser la primera mujer hebrea que alabó a Dios con sus cánticos y por su noble linaje. Rajab es digna de entrar en la Nave por su misericordia, ya que escondió a los espías judíos, enviados de Josué, en su casa y les salvó la vida ${ }^{12}$. Acsá, que se mantuvo virgen y sumisa, hasta su matrimonio con Caleb, obtuvo como dote la ciudad de Dabir y aumentó el patrimonio de su esposo cuando, por mandato suyo, reclamó llorando a su padre los territorios con fuentes naturales de oriente y occidente. Champier coloca a la clarividente Débora, mujer de Lapidot, bajo la jarcia de la Nave porque gracias ella Barac triunfó sobre el rey Yabín y arrasó la ciudad de Aseroth (Hazor), tras lo cual entonaron un cántico para dar gracias y bendecir a Nuestro Señor. Sísara, el jefe del ejército del rey Yabín, huyó a refugiarse a la tienda de Jael, esposa de "Abnercinée»" ${ }^{13}$, mujer sabia y prudente, que le dio leche para beber, lo cubrió con una manta y vigiló la entrada de la tienda para que nadie entrara a prenderlo. Por ello, Jael no debe ser privada de tener un sitio entre las pasajeras de la Nave ${ }^{14}$. De su mano debe entrar la hija de Jefté para reunirse con las demás

${ }^{11}$ La autora de la edición da una entrada a Tharbis la etíope, hija de un rey etíope y esposa de Moisés, destacada por su afabilidad y elocuencia. Explica a tal efecto lo siguiente: «NB. 12:1: Marie et Aaron reprochent à Moïse d'avoir pris une "femme couschite", c'est à dire une femme éthiopienne, Séphora, mais nous n'avons pas trouvé d'Ethiopienne de Tharbe. L'Histoire scholastica parle de Séphora comme uxorem eius ethiopissam, Historia numerorum 16, f. 74». Nota c de la autora, p. 90.

${ }^{12}$ Champier silencia que Rajab era una prostituta.

${ }^{13}$ Abner cineo o Jéber el quenita.

${ }^{14}$ También oculta aquí Champier que le dio muerte clavándole una estaca en la cabeza cuando dormía, cumpliéndose así la profecía de Débora que había predicho que Sisara sería entregado de la mano de una mujer. 
damas. Joven virgen y santa, fue consagrada a Dios por su padre, después de llorar dos meses en la montaña su virginidad, acompañada de otras vírgenes ${ }^{15}$. La mujer de Manoa debe también unirse a las viajeras porque por sus grandes virtudes recibió la visita del ángel que le anunció que concebiría un hijo que sería nazareo de Dios, liberaría al pueblo de Israel y se llamaría Sansón. Noemí es requerida por el autor para añadirla su ramillete de buenas costumbres y virtudes. Esposa del juez y sacerdote Elimelec, fue la más bella de todas las mujeres de Belén y disuadió a su nuera Ruth, que era moabita, de adorar a los ídolos. Ruth era mujer de gran belleza y muy elocuente por lo que fue tomada como esposa por Booz. Es alabada por no dejar sola a su suegra Noemí, cuando esta, al quedar viuda, regresó a la tierra de Judá. Champier no olvida invitar a su Nave a Ester, hija adoptiva de Mardoqueo, elegida entre todas las mujeres para ser la esposa del rey Asuero por su belleza y su encanto, salvó a su pueblo judío del exterminio que planeaba Amán. La hermosura y sabiduría de Judith la hacen digna compañera de travesía. Hija de Merarí y esposa de Manasés, enviudó pronto y se consagró al ayuno respetando la ley de Israel. Su prudencia la llevó a liberar a su pueblo del asedio de Holofernes decapitándolo. Ana, madre de Samuel y esposa de Elcaná, era bella pero estéril. Sus llantos y su plegaria a Dios en el templo de Siló fueron escuchadas por el sacerdote Elí que la creyó ebria. Su honestidad y paciencia ante la recriminación de este fue recompensada y concibió un hijo que ofreció a Elí. Mical, hija de Saúl y esposa de David también formará parte de la Nave por haber salvado la vida a su esposo haciéndolo huir por una ventana, escapando así de los soldados que Saúl había enviado para matarlo. La belleza, elocuencia y sabiduría de Abigail, esposa del cruel Nabal, freno y calmó la ira de David contra su casa. Esas mismas virtudes le valieron ser su esposa a la muerte de Nabal. Por ello no puede faltar en la Nave. Ni ella, ni las otras amadas esposas de David, Ajinoán (o Ahinoam), madre de su primer hijo y descendiente de Jezael, y Betsabé, a la que David deseó tanto que hizo matar a Urías, su esposo para hacerla suya. Fue la madre de Salomón y tanto la honró David que hizo levantar un trono a su derecha para ella. La sabiduría de Tamar le impidió realizar actos deshonestos, por lo que recriminó duramente a su hermano Amnón, hijo de David, que quiso deshonrarla. Ello fue la causa de su muerte de manos de su hermano Absalón, al que su padre desterró, pero tanto fue lo que imploró la mujer de Técoa ante el rey que consiguió su perdón para Absalón. Por su afabilidad y maravillosa elocuencia, Champier la hizo entrar en la Nave y formar parte de su jardín. Abilane ${ }^{16}$ salvó su ciudad, madre de todas las ciudades de Israel, por su sabiduría y prudencia. Recriminó a Joab su intención de destruirla para apresar a Seba, por lo que ella misma, para detener el ataque, persuadió a su pueblo

${ }^{15}$ En la Biblia se explicita que fue sacrificada en holocausto.

${ }^{16}$ En la Biblia, esta mujer no recibe nombre. Kem sospecha que el que le ha dado Champier le viene de ser habitante de la ciudad de Abel Bet Maacá. Ver nota b, página 96. 
de que le cortara la cabeza y ella misma la arrojó por encima del muro a sus enemigos. Las cualidades de bondad y gentileza son el pasaporte de Abisag la Sunamita, elegida de entre todas las hijas de Israel para servir y dar calor al viejo rey David sin intimar con él, según relata Champier. El lugar de la mujer de Sarepta, viuda casta, en la Nave no admite discusión por su acto de hospitalidad con el profeta Elías, al que le dio el pan del que disponía por todo alimento para ella y para su hijo. Por su generosidad, Nuestro Señor multiplicó su comida y devolvió más tarde la vida a su hijo muerto. La mujer de Abdías el profeta, era mujer bondadosa y temerosa de Dios. Ella y su marido alimentaron y ocultaron a cien profetas de la ira del rey Acab, por lo que Elías, a la muerte de su marido, multiplicó su aceite para que pudiera pagar a su acreedor, que quería llevarse con él a sus dos hijos como pago ${ }^{17}$. La sunamita tiene también un lugar en el jardín porque fue una egregia dama de cuerpo y de nobleza. Alojó y sirvió a Elías en su casa y él la recompensó con un hijo que murió pronto, pero volvió a la vida gracias al profeta. Ana, la mujer de Tobías, es otra de las elegidas por su laboriosidad, gracias a la cual mantuvo su casa. Además, fue una mujer muy piadosa que lloraba todos los días esperando la vuelta de su hijo hasta que éste llegó. Sarra, hija de Ragüel, tuvo, antes de esposar a Tobías, que rezar y ayunar durante tres días pidiéndole a Dios que guardara a su marido del diablo Asmodeo, que ya había matado antes a sus siete maridos en la noche de bodas llevado por el deseo, pues Sarra era extremadamente bella y gentil. La hija de Jelcías y mujer de Joaquín, Susana, tampoco podía faltar en la Nave porque prefirió morir que cometer adulterio con los viejos, que cometieron falso testimonio para que la hicieran lapidar. Pero por su confianza en Dios fue salvada por el profeta Daniel y los viejos condenados a la muerte que para ella desearon. La memoria de la mujer macabea debe ser conservada y admirada porque prefirió ver morir, a sus siete hijos, exhortándolos a ser fuertes y a enfrentarse a la muerte, por no consentir faltar a la ley comiendo carne de cerdo, tras lo cual ella también fue objeto de martirio. No es pues, extraño, añade Champier, que ella también se añada a sus flores por ser tan virtuosa. Ana, la hija de Fanuel, de la tribu de Aser, tiene también derecho a entrar en la Nave porque fue una mujer muy casta y en su larga viudez sirvió a Dios noche y día con ayunos y oraciones. Por último, Isabel, la madre de san Juan Bautista y esposa de Zacarías, ocupa un lugar de honor en la Nave. Descendiente del linaje de Aarón, fue estéril hasta que ya anciana Dios le dio un hijo que la libró del oprobio de los hombres. Dentro de su vientre, su hijo se regocijó cuando oyó el saludo de Nuestra Señora. Por ello santa Isabel, inspirada por el Espíritu Santo, le dijo: «Tu es benoiste entre toutes les femmes et benoist est le fruit de ton ventre».

\footnotetext{
${ }^{17}$ Champier confunde la identidad de varias mujeres bíblicas.
} 


\section{COINCIDENCIAS Y DISIDENCIAS \\ DE LOS MODELOS FEMENINOS \\ EN ESTOS Y OTROS TRATADOS MEDIEVALES}

Las diferencias del tratamiento de estos exempla entre ambos autores vienen dadas en primer lugar por la propia concepción y diferente estructura de las obras. La Marche hace en sus glosas en prosa un largo desarrollo de los hechos que rodearon a las protagonistas, mientras que Champier se limita a una breve síntesis en la que omite aspectos fundamentales de la historia, para solo destacar los elementos que le son de provecho para resaltar las virtudes que desea ensalzar. De hecho, la selección es también significativa: mientras que el primero identifica veintidós complementos de la vestimenta femenina con una virtud, que atribuye a una figura femenina, de las que sólo tres son mujeres del Antiguo Testamento, en la Nef se pasa revista a buena parte de ellas llegándose a mencionar hasta treinta y ocho. Sólo tres de ellas -Abigail, Judith y Esther-son comunes a ambos textos. En todos los casos, La Marche incide en los hechos llevados a cabo por las mujeres, mientras que Champier hace hincapié en su relación con padres y esposos.

En el caso de la primera ambos autores coinciden en oponer la ofuscación y la crueldad de Nabal frente a la actuación rápida de su esposa para salvar su casa y sus bienes de la inminente destrucción ordenada por David. Convienen también en hacer alusión a la recompensa que obtuvo Abigail por este hecho, que David la tomara por esposa, si bien Champier añade que la belleza, la elocuencia y la sabiduría de Abigail también influyeron en su decisión.

En el relato de Judith, La Marche insiste en el hecho de que hacer justicia debe ser un deber tanto para el hombre como para la mujer, especialmente si se trata de hacerla por el bien común. En descargo del brutal crimen cometido por una mujer, La Marche arguye que esta bella viuda, casta y virtuosa, actuó movida por vengar a su Dios y librar al mundo del tirano, pero además añade que Judith blandió la espada «non pas comme femme et en meurs feminines, mais comme changee en couraige et force d'homme». Para Champier, la decapitación de Holofernes fue un acto de prudencia llevado a cabo por una mujer respetuosa con las leyes judías y temerosa de Dios, que tuvo como consecuencia la salvación del pueblo de Israel.

Para realzar las bondades de Ester, La Marche relata primero el episodio de la desobediente Vasti, la primera mujer de Asuero. Ambos autores convienen que su principal virtud es la obediencia, a lo que se añade en el caso de La Marche, su actitud recatada y sumisa y su extraordinaria hermosura, si bien para Champier esta última, la belleza física, fue la causa que prevaleció para salvar al pueblo judío de la amenaza de exterminio.

En este breve análisis comparativo observamos bastantes coincidencias ya que ambos autores respetan el imaginario colectivo para cada una de estas tres figuras, símbolos de la cultura cristiana, que se encuentran también en otros tratados medievales. 
Así, y siguiendo un orden cronológico, encontramos a estas tres heroínas bíblicas en Le Ménagier de Paris (1339) ${ }^{18}$, cuyo anónimo autor, las incluye en un relato más largo, el célebre cuento de Prudencia y Melibeo, del que el autor hace uso para ilustrar el ejemplo de la buena esposa que da sabios consejos a su marido. A los deseos de venganza de Melibeo, provocados por la agresión sufrida por su propia esposa y su hija, Prudencia le aconseja que no tome decisiones precipitadas, pero su esposo, apoyándose en autoridades, como Salomón o Jesús, el hijo de Sirac, le replica que no existe ni una sola mujer buena y que si siguiera su recomendación lo tomarían por loco y creerían que estaba dominado por ella; además, si lo hiciera en secreto, ella lo revelaría a todo el mundo porque las mujeres no saben ser reservadas ni aconsejar sabiamente. Prudencia refuta este último argumento, dándole pruebas de la existencia de mujeres virtuosas que han sabido proporcionar sensatos consejos y actuar sabiamente. Es el caso, entre otras, de Judith, que liberó a la ciudad de Betulia de la ira de Holofernes; Abigail, que salvó a su esposo Nabal y apaciguó al rey David; y Ester $^{19}$, que, gracias a su sabiduría, logró que el pueblo judío prosperara en el reino de Asuero.

En Le Livre Chevalier de La Tour-Landry pour l'enseignement de ses filles (1371$1372)^{20}$, el título del capítulo 82 "Que toute femme doit soustenir son seigneur» (p. 180) es ilustrativo en cuanto expresa ya en un tono impositivo uno de los deberes de la esposa, apoyar a sus maridos, ya sea cruel, pendenciero y difamador. Aun así, la buena esposa debe protegerlo de los peligros que el mismo se busca por su desatino, sufrir en silencio y soportar humildemente sus desagravios. La conducta de Abigail es la que propone como ejemplo de este comportamiento sumiso. La Tour-Landry no hace mención de la figura de Judith ni siquiera dentro del grupo de las malas mujeres, aquellas que, según nuestro autor, provocaron grandes males a la humanidad (capítulos XXXVII a LXXXI), lo que no hubiese sido consecuente en el caso de Judith, que salvó a su pueblo de la amenaza de Holofernes y que es uno de

${ }^{18}$ Esta obra es un tratado de educación moral y doméstica que su autor, al parecer un hombre de edad avanzada, escribe para su joven esposa, de quince años, con el fin de instruirla, tanto en aspectos morales como domésticos, y para que sus enseñanzas también le sirvan de provecho en un segundo matrimonio que, según sus conjeturas, tendrá lugar después de su muerte, dada la diferencia de edad entre ambos.

19 Sobre Ester en los tratados de educación femenina medievales, véase nuestro artículo: González Doreste y Plaza Picón, 2018.

${ }^{20}$ En este tratado, como su propio título indica, un padre se dirige a sus hijas, dándoles buenos consejos para que lleguen a ser buenas esposas y madres, principales funciones de la mujer medieval. Siguiendo la tradición del discurso didáctico, se vale de heroínas tanto de la antigüedad clásica, como de la Biblia, de la historia o incluso de algunas contemporáneas, que propone como modelos de conducta laudables o, por el contrario, como ejemplos reprobables. 
los modelos virtuosos que aparece en la mayoría de los tratados ${ }^{21}$. Evidentemente, tanto Abigail como Ester están dentro de la categoría de las virtuosas, cuyas conductas son un modelo para las demás. La Tour-Landry sacará buen provecho del relato de Ester, a la que dedica el capítulo 87, pero también a Vasti (capítulo 64), que obviamente está entre las mujeres de conducta reprobable, así como la esposa de Amán (capítulo 65). No se detiene tanto en el relato de los hechos protagonizados por estas mujeres, sino en las enseñanzas que de ellos puede extraer para sus hijas. Como ya hemos expuesto en un trabajo anterior: «Su intención es elaborar un discurso moralizador que destaque las tres virtudes que honran a la buena esposa: complacer al esposo en todos sus deseos, ser fiel y casta para no poner su honor en entredicho y no avergonzarlo públicamente con modales o palabras altisonantes» (González Doreste y Plaza Picón, 2018: 52).

Christine de Pizan, en su obra La cité des dames (1405), tiene como principal fuente el libro de Boccaccio De Claris Mulieribus (1361-62). Sin embargo, en nada influye el italiano en las figuras femeninas que estamos tratando puesto que no introduce en su retablo ningún personaje bíblico. Sus ideologías son opuestas, al menos en lo que se refiere a su concepción de la valía femenina, identificándose él con los presupuestos misóginos de los autores que hemos ido mencionando y queriendo ella desmontarlos. Mientras que Boccaccio atribuye la inferioridad de la mujer a su propia naturaleza, que las hace voluptuosas, frágiles de cuerpo y lentas de mente, Christine lo imputa al orden social establecido que priva a la mujer el acceso al conocimiento y la somete a la reclusión y a las tareas propias del espacio doméstico y sólo la considera útil para la procreación y la educación de los hijos e hijas en sus primeros años. Si uno considera que sólo la memoria de algunas de ellas merece ser conservada por haber llevado a cabo hechos extraordinarios y anómalos para una mujer, inspirados sobre todo por su espíritu viril, la otra pretende demostrar que las mujeres tienen las mismas capacidades que los hombres y, por medio de sus exempla, se propone dignificar la imagen femenina ${ }^{22}$. Tomamos las palabras de Ana Vargas Martínez para resumir la enorme aportación que supuso la obra de Christine de Pizan en la defensa de las mujeres y en la posterior Querella de las Mujeres:

${ }^{21}$ Anne-Marie de Gend considera que la omisión de los capítulos de Judith y de santa Ana, que figuran en la fuente de la que se inspira La Tour- Landry, Le miroir des bonnes femmes, escrito en la segunda mitad del siglo XIII por un anónimo franciscano, "paraît relever d'un choix conscient et non d'un oubli. Nous en voulons pour preuve le fait que la coutume romaine qui consistait à couronner les veuves méritoires pour consacrer leur chasteté, nommée dans le chapitre sur Judith, est quand même mentionnée dans le Livre, et ce à la fin de la section basée sur le Miroir (219, 6-11). Manifestement le Chevalier a préféré réserver les observations théoriques sur la chasteté pour la troisième partie de son Livre (cf. Chap. 4)» (2003: 157).

${ }^{22}$ Véase a este respecto nuestro trabajo: González Doreste, 2018. 
Con esta obra se inauguró un nuevo discurso de lo femenino, se introdujeron nuevos contenidos que marcaron la tonalidad del debate y, sobre todo, con ella, Christine de Pizan creó una nueva autoridad que extrajo de su propia experiencia, una experiencia femenina que reconoce y valora como fuente de saber (2009: 22).

En la segunda parte de La cité des dames (capítulo 30), Christine se extraña ante Derechura de cómo habiendo proporcionado tantos beneficios a la humanidad, los hombres siguen afirmando que las mujeres son fuente de todos los males. Su interlocutora le responde que ya ha dado pruebas de cómo las mujeres han prestado múltiples servicios en el campo de las artes y las ciencias. No obstante, añade, le dará más testimonios, en este caso sobre sus contribuciones espirituales. Es aquí donde entran Judith y Ester, mujeres elegidas por Dios para liberar a su pueblo. En el caso de «la noble veuve Judith» (p. 169), Christine destaca su valentía. La biografía de «la noble et sage reine Esther» (p. 171), liberadora igualmente del pueblo judío "que le roi Assuérus tenait alors en esclavage» (p. 171), pone en valor también otras cualidades como su belleza y su humildad, de las que hizo uso para doblegar la voluntad de su marido ${ }^{23}$.

\section{CONCLUSIONES}

Es revelador que Symporien Champier comience su larga lista de modelos femeninos tomados de la Biblia con la figura de Eva, formada a partir de un hombre íntegro y honesto, según el autor, pero desencadenante de todo el dolor del género humano por su desobediencia, y termine con el encuentro de Isabel con María, prototipo de la mujer perfecta, compendio de todas las virtudes femeninas y que será la madre del salvador de la humanidad. Entre ellas dos, todas estas mujeres que destacan por sus virtudes individuales que son, en efecto, las que los autores quieren inculcar a sus lectoras. Se trata de mujeres fuertes, capaces de hazañas singulares, que son alabadas y enaltecidas siempre que sus acciones se ejecuten en beneficio de su pueblo, de su esposo, o de su rey.

Su visibilidad e identidad social están supeditadas al varón, a su condición de ser hija, esposa, hermana o madre. Incluso muchas de ellas no tienen nombre, sino que son mencionadas por su relación con el hombre, cualquiera que sea su filiación familiar con él.

${ }^{23}$ Christine menciona a Ester, no sólo en La cité des dames, sino en varias de sus obras como Le Livre des trois Vertus (1405), donde la reina judía es ejemplo de esposa obediente y de mujer casta, o en la Mutation de Fortune (1403), en la que también cuenta la historia de la reina Ester. También lo hace en L'Epistre à la Reine (1405), donde le da el papel de intermediaria en un conflicto bélico. Véase González Doreste y Plaza Picón, 2018: 55. 
A través de ellas, no solo se configuran los valores que la sociedad patriarcal aprecia en las mujeres (perseverancia, castidad, discreción, modestia, sumisión, piedad, etc.), sino que también se ofrecen unos modelos de virtud para que, imitándolos, las mujeres corrijan los defectos y taras inherentes propios de su naturaleza (pereza, negligencia, frivolidad, inestabilidad, lascivia, etc.). No olvidemos que en esa época la ciencia médica, basada en la teoría de los cuatro humores, atribuía a las mujeres menor inteligencia y predisposición, como bien señala el opúsculo latino Secreta Mulierum, de principios del siglo XIV, cuyas teorías seguirán vigentes hasta bien entrado el siglo XVI y al que Christine de Pizan se atreve a tildar de sarta de estupideces y mentiras.

De esta manera, en los textos estudiados, se proyecta un retrato ideal de la mujer en función del estatus que ocupa o que debe ocupar en la sociedad y se les imponen unos rígidos códigos de conducta. Las jóvenes deben mantenerse puras y castas hasta el momento de su casamiento o permanecer así toda la vida si se consagran a Dios o no tienen la suerte de encontrar un marido. Las mismas exigencias son requeridas para las mujeres viudas que, además, pasan a ser figuras marginales y excluidas de la sociedad. El estatus ideal de la mujer es el matrimonio y dentro de él, su función más importante es ser madre. Las cualidades que deben prevalecer en ellas como esposas son la sumisión, la obediencia y la complacencia hacia el esposo.

Hemos visto cómo muchas de las mujeres mencionadas son recompensadas bien con un marido y/o con un hijo, pues ser estéril es un oprobio para ellas. Su sabiduría, sus habilidades retóricas y su belleza son apreciadas en cuanto son puestas al servicio de la liberación de su pueblo o para auxiliar a sus maridos en los heroicos cometidos que deben llevar a cabo. En estos casos, todo vale y la seducción será un arma femenina esencial, como en el caso de Judith y Ester, así como el vigor y la fortaleza física siempre que se ejercite por un ideal de justicia (Judith).

A través de estos exempla, los escritores refuerzan un arquetipo de mujer, todavía vigente en algunos sectores de la sociedad, que se adapta al discurso patriarcal, utilizando modelos femeninos que pertenecen a la tradición cristiana manipulados a su gusto. Estamos de acuerdo con Elizabeth Kinne en admitir que aunque los escritores se dirijan a un público femenino, también lo hace para que los varones reconozcan en estos tratados su principio de autoridad moral masculina en el ámbito doméstico (2010: 150).

Sólo Christine de Pizan toma la palabra en nombre de todas las mujeres, desafiando a las autoridades y teorías de su tiempo, para reivindicar un espacio, una Ciudad de Damas, donde ellas sean consideradas iguales en capacidades y dignidad que los hombres y concediéndoles un lugar en la historia por derecho propio.

RECIBIDO: julio 2019; ACEPTADO: septiembre 2019.

\section{REFERENCIAS BIBLIOGRÁFICAS}

Álvarez JuRADO, M.Á. (2001): «Didactismo y erudición femenina en el Renacimiento francés». Alfinge. Revista de Filología 13 (13): 7-24. 
BReitenstein, R. C. (2016): «Tensions fécondes dans la construction de publics féminins à l'aube de la Renaissance française: les exemples de La Nef des dames vertueuses de Symphorien Champier et de La Louenge de mariage et recueil des hystoires des bonnes, vertueuses et illustres femmes de Pierre de Lesnauderie», in Les fermmes, la culture et les arts en Europe entre Moyen Âge et Renaissance, sous la direction de Cynthia J. Brown \& Anne-Marie Legaré, Brepols, 241-257.

CARLINO, A., \& Wenger, A. (eds.) (2007): Littérature et médecine: approches et perspectives (XVI ${ }^{e}$-XIX siècle) (vol. 24), Librairie Droz, Genève.

Champier, Symphorien (2007): La nef des dames vertueuses, éd. Judy KeM, Honoré Champion, Paris.

GAUCHER, É. (2006): «Olivier de la Marche et l'allégorie: pour une lecture à clés du Triumphe des Dames», in Les clefs des textes médiévaux: Pouvoir, savoir et interprétation [online], Presses universitaires de Rennes, Rennes.

GendT, A. M. DE (2003): L'art d'éduquer les nobles damoiselles. Le livre du Chevalier de la Tour-Landry, Honoré Champion, Paris.

GonzÁlez Doreste, D. M. (2019): «Escritoras en busca de espacio: Proba la Romana, Christine de Pizan y Woolf», en Milagro Martín Clavijo y Yolanda Romano Martín (coords.), Escritoras y personajes femeninos en la literatura. Retos y pluralidad, Colección Interlingua, Comares, Granada, cap. 15, pp. 119-127.

GonZÁlez Doreste, D. M. y Plaza Picón, F. M. (2018): «Modelos bíblicos de mujer: Ester y la salvación del pueblo judío", Forma Breve. Em busca da terra prometida: mitos de salvacao 15: 45-58.

KINNE, E. (2010): «Les écrits didactiques pour femmes et le double discours du désir au Moyen Âge», Clio. Femmes, Genre, Histoire 31: 135-152.

LA MARCHE, Olivier DE (1901): Le triumphe des Dames von Olivier de la Marche, édition de J. KALBFLEISCHBENAS, Adler's Erben, Rostock.

La Tour LANDrY, Geoffroy DE (1854): Le Livre du Chevalier de La Tour Landry pour l'enseignement de ses filles, publié d'après les manuscrits de Paris et de Londres par M. Anatole DE MONTAIGLON, Jannet, Paris.

Le Mesnagier de Paris (2010): G. E. Brereton \& J. M. Ferrier (eds.), Le Livre de Poche, Lettres Gothiques, Paris.

PIZAN, Christine DE (1986): La Cité des Dames, traduction, introduction par É. HiCKS et T. MOREAU, Paris, Stock (Stock Moyen Âge) [réimpr.: 1992; 1996; 2000].

Serrano, F. (2009): «Le triumphe des dames traduit par Fernand de Lucène et les Cent Nouvelles nouvelles au cœur de la Querelle des Femmes bourguignonne», Réforme, Humanisme, Renaissance 69 (1): 55-71.

STEIN, H. (1888): Olivier de La Marche, historien, poète et diplomate bourguignon, A. Picard éditeur, Paris.

Tyl-Labory, G. (1992): "Olivier de La Marche», Dictionnaire des lettres françaises: le Moyen Âge, éd. Geneviève Hasenohr et Michel ZINK, Fayard, Paris, pp. 1085-1086 [Réimpr.: Fayard, (La Pochothèque), Paris, 1994].

Vargas Martínez, A. (2010): «La Ciudad de las Damas de Christine de Pizan: Obra clave de la Querella de las Mujeres», en C. SEgura Graíño (coord.), La Querella de las mujeres: Análisis de textos, Asociación Cultural Al-Mudayna, Madrid, pp. 21-47. 